\title{
The Quadruple Aim: care, health, cost and meaning in work
}

\author{
Rishi Sikka, ${ }^{1}$ Julianne M Morath, ${ }^{2}$ Lucian Leape $^{3}$
}

\begin{abstract}
${ }^{1}$ Advocate Health Care, Downers Grove, Illinois, USA

${ }^{2}$ Hospital Quality Institute, Sacramento, California, USA ${ }^{3}$ Harvard School of Public Health, Boston, Massachusetts, USA
\end{abstract}

\section{Correspondence to} Dr Rishi Sikka, Advocate Health Care, 3075 Highland Avenue, Suite 600, Downers Grove, II 60515, USA; rishi.sikka@advocatehealth.com

Received 5 March 2015 Revised 6 May 2015

Accepted 16 May 2015

\section{CrossMark}

To cite: Sikka R, Morath JM, Leape L. BMJ Qual Saf 2015;24:608-610.
In 2008, Donald Berwick and colleagues provided a framework for the delivery of high value care in the USA, the Triple Aim, that is centred around three overarching goals: improving the individual experience of care; improving the health of populations; and reducing the per capita cost of healthcare. ${ }^{1}$ The intent is that the Triple Aim will guide the redesign of healthcare systems and the transition to population health. Health systems globally grapple with these challenges of improving the health of populations while simultaneously lowering healthcare costs. As a result, the Triple Aim, although originally conceived within the USA, has been adopted as a set of principles for health system reform within many organisations around the world.

The successful achievement of the Triple Aim requires highly effective healthcare organisations. The backbone of any effective healthcare system is an engaged and productive workforce. ${ }^{2}$ But the Triple Aim does not explicitly acknowledge the critical role of the workforce in healthcare transformation. We propose a modification of the Triple Aim to acknowledge the importance of physicians, nurses and all employees finding joy and meaning in their work. This 'Quadruple Aim' would add a fourth aim: improving the experience of providing care.

The core of workforce engagement is the experience of joy and meaning in the work of healthcare. This is not synonymous with happiness, rather that all members of the workforce have a sense of accomplishment and meaning in their contributions. By meaning, we refer to the sense of importance of daily work. By joy, we refer to the feeling of success and fulfilment that results from meaningful work. In the UK, the National Health Service has captured this with the notion of an engaged staff that 'think and act in a positive way about the work they do, the people they work with and the organisation that they work in'. ${ }^{3}$
The evidence that the healthcare workforce finds joy and meaning in work is not encouraging. In a recent physician survey in the USA, $60 \%$ of respondents indicated they were considering leaving practice; $70 \%$ of surveyed physicians knew at least one colleague who left their practice due to poor morale. ${ }^{2}$ A 2015 survey of British physicians reported similar findings with approximately $44 \%$ of respondents reporting very low or low morale. ${ }^{4}$ These findings also extend to the nursing profession. In a 2013 US survey of registered nurses, $51 \%$ of nurses worried that their job was affecting their health; 35\% felt like resigning from their current job. ${ }^{5}$ Similar findings have been reported across Europe, with rates of nursing job dissatisfaction ranging from $11 \%$ to $56 \% .^{6}$

This absence of joy and meaning experienced by a majority of the healthcare workforce is in part due to the threats of psychological and physical harm that are common in the work environment. Workforce injuries are much more frequent in healthcare than in other industries. For some, such as nurses' aides, orderlies and attendants, the rate is four times the industrial average. ${ }^{7}$ More days are lost due to occupational illness and injury in healthcare than in mining, machinery manufacturing or construction. ${ }^{7}$

The risk of physical harm is dwarfed by the extent of psychological harm in the complex environment of the healthcare workplace. Egregious examples include bullying, intimidation and physical assault. Far more prevalent is the psychological harm due to lack of respect. This dysfunction is compounded by production pressure, poor design of work flow and the proportion of non-value added work.

The current dysfunctional healthcare work environment is in part a by-product of the gradual shift in healthcare from a public service to a business model that occurred in the latter half of the 20th 
century. ${ }^{8}$ Complex, intimate caregiving relationships have been reduced to a series of transactional demanding tasks, with a focus on productivity and efficiency, fuelled by the pressures of decreasing reimbursement.

These forces have led to an environment with lack of teamwork, disrespect between colleagues and lack of workforce engagement. The problems exist from the level of the front-line caregivers, doctors and nurses, who are burdened with non-caregiving work, to the healthcare leader with bottom-line worries and disproportionate reporting requirements. Without joy and meaning in work, the workforce cannot perform at its potential. Joy and meaning are generative and allow the best to be contributed by each individual, and the teams they comprise, towards the work of the Triple Aim every day.

The precondition for restoring joy and meaning is to ensure that the workforce has physical and psychological freedom from harm, neglect and disrespect. For a health system aspiring to the Triple Aim, fulfilling this precondition must be a non-negotiable, enduring property of the system. It alone does not guarantee the achievement of joy and meaning, however the absence of a safe environment guarantees robbing people of joy and meaning in their work. Cultural freedom from physical and psychological harm is the right thing to do and it is smart economics because toxic environments impose real costs on the organisation, its employees, physicians, patients and ultimately the entire population.

An organisation focused on enabling joy and meaning in work and pursuit of the Triple Aim needs to embody shared core values of mutual respect and civility, transparency and truth telling and the safety of the workforce. It recognises the work and accomplishments of the workforce regularly and with high visibility. For the individual, these notions of joy and meaning in healthcare work are recognised in three critical questions posed by Paul O'Neill, former chairman and chief executive officer of Alcoa. This is an internal gut-check, that needs to be answered affirmatively by each worker each day: ${ }^{2}$

1. Am I treated with dignity and respect by everyone, everyday, by everyone I encounter, without regard to race, ethnicity, nationality, gender, religious belief, sexual orientation, title, pay grade or number of degrees?

2. Do I have the things I need: education, training, tools, financial support, encouragement, so I can make a contribution this organisation that gives meaning to my life?

3. Am I recognised and thanked for what I do?

If each individual in the workforce cannot answer affirmatively to these questions, the full potential to achieve patient safety, effective outcomes and lower costs is compromised.

The leadership and governance of our healthcare systems currently have strong economic and outcome motivations to focus on the Triple Aim. They also need to feel a parallel moral obligation to the workforce to create an environment that ensures joy and meaning in work. For this reason, we recommend adding a fourth essential aim: improving the experience of providing care. The notion of changing the objective to the Quadruple Aim recognises this focus within the context of the broader transformation required in our healthcare system towards high value care. While the first three aims provide a rationale for the existence of a health system, the fourth aim becomes a foundational element for the other goals to be realised.

Progress on this fourth goal in the Quadruple Aim can be measured through metrics focusing on two broad areas: workforce engagement and workforce safety. Workforce engagement can be assessed through annual surveys using established frameworks that allow for benchmarking within industry and with non-healthcare industries. ${ }^{9}$ Measures should also be extended to quantify the opposite of engagement, workforce burn-out. This could include select questions from the Maslach Burnout Inventory, the gold standard for measuring employee burn-out. ${ }^{10}$ In the realm of workforce safety, metrics should include quantifying work-related deaths or disability, lost time injuries, government mandated reported injuries and all injuries. Although these measures do not completely quantify the experience of providing care, they provide a practical start that is familiar and allow for an initial baseline assessment and monitoring for improvement.

The rewards of the Quadruple Aim, achieved within an inspirational workplace could be immense. No other industry has more potential to free up resources from non-value added and inefficient production practices than healthcare; no other industry has more potential to use its resources to save lives and reduce human suffering; no other industry has the potential to deliver the value envisioned by The Triple Aim on such an audacious scale. The key is the fourth aim: creating the conditions for the healthcare workforce to find joy and meaning in their work and in doing so, improving the experience of providing care.

Contributors All authors assisted in the drafting of this manuscript.

Competing interests None declared.

Provenance and peer review Not commissioned; externally peer reviewed.

\section{REFERENCES}

1 Berwick DM, Nolan TW, Whittington J. The triple aim: care, health and cost. Health Aff 2008;27:759-69.

2 Lucian Leape Institute. 2013. Through the eyes of the workforce: creating joy, meaning and safer health care. Boston, MA: National Patient Safety Foundation.

3 NHS employers staff engagement. http://www.nhsemployers. org/staffengagement (accessed 4 May 2015).

4 BMA Quarterly Tracker Survey. http://bma.org.uk/workingfor-change/policy-and-lobbying/training-and-workforce/ 


\section{Editorial}

tracker-survey/omnibus-survey-january-2015 (accessed 4 May 2015).

5 AMN Healthcare 2013 survey of registered nurses. http://www. amnhealthcare.com/uploadedFiles/MainSite/Content/ Healthcare_Industry_Insights/Industry_Research/2013_ RNSurvey.pdf (accessed 4 May 2015).

6 Aiken LH, Sermeus W, Van Den HeedeKoen, et al. Patient safety, satisfaction and quality of hospital care: cross sectional surveys of nurses and patients in 12 countries in Europe and the United States. BMJ 2012;344:e1717.

7 US Department of Labor Bureau of Labor Statistics. Occupational injuries and illnesses (annual) news release.
Workplace injuries and illnesses 2009. 21 October 2010. http://www.bls.gov/news.release/archives/osh_10212010.htm (accessed 4 May 2015).

8 Morath J. The quality advantage, a strategic guide for health care leaders. AHA Press, 1999:225.

9 Surveys on Patient Safety Culture. Agency for Healthcare Research and Quality. http://www.ahrq.gov/professionals/qualitypatient-safety/patientsafetyculture/index.html (accessed 4 May 2015).

10 Maslach C, Jackson S, Leiter M. Maslach burnout inventory manual. 3rd edn. Palo Alto, CA: Consulting Psychologists Press, 1996. 